\title{
Factors Affecting the Metal Recovery Yield During Induction Melting of Aluminium Swarf
}

\author{
Hélder Puga ${ }^{1 \mathrm{a}}$, Joaquim Barbosa ${ }^{1, \mathrm{~b}}$ and Carlos Silva Ribeiro ${ }^{2, \mathrm{c}}$ \\ ${ }^{1}$ CT2M - Centre for Mechanical and Materials Technologies, Universidade do Minho, 4800-058 \\ Guimarães, Portugal \\ ${ }^{2}$ FEUP, Departamento de Engenharia Metalúrgica e de Materiais, 4200-465 Porto, Portugal \\ apuga@dem.uminho.pt, bkim@dem.uminho.pt, csribeiro@fe.up.pt
}

Keywords: Aluminium swarf; Recycling; Melting; Environment

\begin{abstract}
Machining operations of cast parts usually generate considerable amounts of waste in the form of chips (usually 3-5\% of the casting weight). Traditionally, swarf is sold to scrapers and remelters, but this option is quite expensive because the selling price is roughly $30 \%$ of the acquisition price of the commercial 2 nd melt raw material. For most aluminium foundries that incorporate machining operations in their products, reusing aluminium chips as raw material for the melting stocks is perhaps the best option as waste management policy in what concerns to economical and technical aspects. Nevertheless, aluminium swarf is a low density product $\left(0.25 \mathrm{~kg} / \mathrm{dm}^{3}\right)$ and is usually covered by a thin film of aluminium oxide and machining fluid. Melting such a product without suitable previous preparation leads to very low metal recovery rates, high energy consumption, gases and smoke generation and very low quality of the final product.

During the last years, the authors have developed a high efficient and environmentally friend aluminium swarf recycling technique, using direct incorporation in aluminium melts. The influence of processing parameters, namely melt temperature and holding time, melting atmosphere, swarf briquetting pressure and melting charge composition in the metal recovery yield and dross generation was studied and characterized, and the optimal processing parameters were established. The microstructure of the final product obtained in those conditions was evaluated and is also presented.

It is shown that the recycling efficiency depends on the swarf conditioning, the melting technique and the melt treatment methodology. Swarf moisture reduction, induction melting under protective atmosphere and a specially developed degassing technique were found the most important factors influencing the recycling process. By using the developed technique, cast ingots with microstructure and sanity similar to commercially available AlSi12Cu1 2nd melt raw material were successfully obtained with minimal dross formation and metal recovery rates around $90 \%$, without using traditional salts and fluxes.
\end{abstract}

\section{Introduction}

The aluminium industry is undoubtedly playing a major role in the global economy. According to Aluminium Association, almost 50 million tonnes of aluminium products are produced annually around the world, 30\% corresponding to recycled products [1]. Moreover, the exceptional changes that we are assisting in the transportation industry will surely increase those figures in a very close future. The worldwide position of aluminium and aluminium alloys is a consequence of their well known advantages over other competitive materials in most aspects, such as high tensile properties and corrosion resistance, light weight and good workability, namely by machining, casting and welding techniques [2].

Recycling of aluminium products has been a key issue to develop this market, mainly due to major economical savings by comparison with the buying cost of primary raw material. The most interesting aspect of aluminium recycling is the huge energy saving when compared with the energy costs to transform bauxite or alumina into primary aluminium. The same amount of secondary aluminium produced from recycled metal requires approximately $5 \%$ of the energy when compared 
to primary aluminium production [3]. Therefore, it is commonly accepted that the key issue to build up a sustainable aluminium industry is the development of both easily recyclable Al based alloys and environmentally friend low cost recycling techniques, which will have a decisive impact to the Life Cycle Inventory (LCI) of aluminium components [4].

The traditional route to recycle aluminium products and sub-products, like beverage cans, scrap and machining chips is melting them in rotary furnaces which are usually heated by burning fossil fuels. Salts or salt mixtures with low melting temperature are usually added to the melting stock in order to break down the oxide films and promoting the metal-slag separation, thus enhancing the metal recovery yield of the operation. The use of salts leads to the formation of a byproduct known as "salt cake" which is a hazardous waste and has an extremely high alienation cost. After melting, the liquid metal is degassed and refined using suitable products for each type of alloy, normally Al-Ti-B and Al-Sr master alloys and poured into metallic moulds. At the end, aluminium loss can easily reach 50\% [5], making this traditional recovery procedure highly inefficient, besides presenting high environmental impact.

Alternative approaches have been developed during the last years, like granulation and direct conversion into extruded [5-8] or rolled products [9] or induction melting using fluxes [3].

On this work an environmentally friend aluminium swarf recycling technique that avoids the use of salts during melting is presented. Machining swarf was induction melted, and ultrasounds were used to break the oxide films and promote degassing, using a technique published elsewhere [10]. Those techniques and procedures are the major advantages over the current industrial practices. In order to attain considerable decreasing of manufacturing costs, the final recovered product is introduced in the production cycle together with remaining raw materials.

\section{Experimental Procedure}

Swarf Conditioning. Machining swarf was first collected from the machining centres and allowed to decant for 12 hours, in order to reduce the moisture content, and centrifuged for 10 minutes at $400 \mathrm{rpm}$. After this operation, it was compacted into $50 \times 50 \times(\approx 90) \mathrm{mm}$ briquettes using 300,400 and 500 bar.

Melting Operation. Melting of the swarf briquettes was carried out in a $1500 \mathrm{~Hz}, 50 \mathrm{~kW}, 10$ litre induction furnace, using a SiC crucible as lining. Before introducing the first briquettes, a small volume of molten bath of $\mathrm{AlSi} 12 \mathrm{Cu} 1$ was produced using casting returns. Briquettes were then introduced into the melt using a specially designed automatic feeder (Fig.1) that allowed the briquettes to completely melt inside the liquid, without contact with the atmosphere. At the same time, a ceramic acoustic sonotrode connected to a wave guide, a transducer and a ultrasonic generator was introduced in the melt to induce high frequency vibration in the melt in order to break the swarf oxide films and simultaneously promote continuous degassing (Fig.2). Ultrasonic processing was performed at $19.9 \mathrm{kHz}$ and $1 \mathrm{~kW}$ electric power. Total melting time after introducing the first briquette varied from 30 to 60 minutes depending on the compression strength used for briquetting, the composition of the melting charge and the melt temperature. Melt temperatures of 750,800 and $850^{\circ} \mathrm{C}$ and 5 minutes holding time (after melting the last briquette) for homogenization and final degassing were evaluated.

After that period, the melt was allowed to cool to $730^{\circ} \mathrm{C}$, for final degassing, grain refinement and microstructure modification. An addition of Al-Ti-B master alloy corresponding to Ti addition of $0.03 \%$ was used for grain refinement. Si modification was carried out by adding $0.03 \mathrm{Sr}$ under the form of Al5Sr master alloy. Finally, besides pouring Al ingots, cylindrical test samples with $20 \mathrm{~mm}$ diameter and $80 \mathrm{~mm}$ length were cast in permanent metallic moulds pre-heated to $250^{\circ} \mathrm{C}$ for microstructure characterization and chemical analysis evaluation. Samples to evaluate the degassing efficiency were also taken at the same time. 


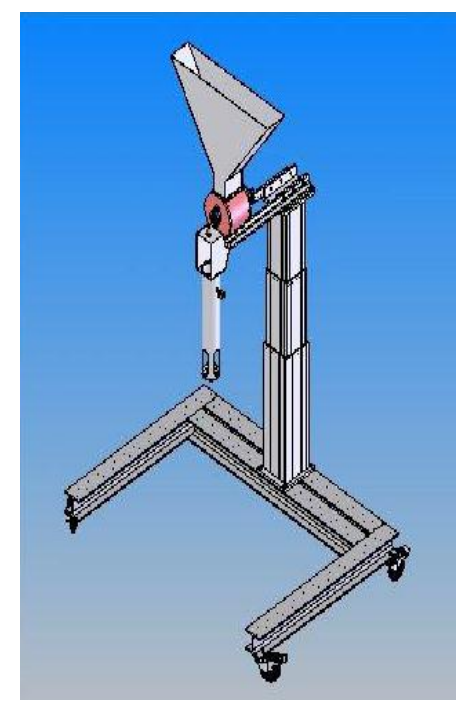

Figure 1 - Schematic overview of the automatic briquette feeder

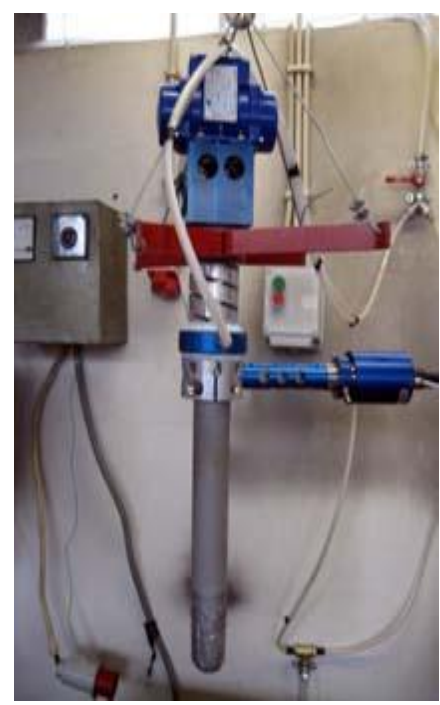

Figure 2 - Ultrasonic degassing unit

Characterization Techniques. The gas content of the samples was evaluated by measuring their density, using the "Straube-Pfeiffer" (RPT) test and the apparent density measurement method.

Samples for microstructure evaluation were prepared by sectioning the cylinders perpendicularly to its longitudinal axis. They were ground using $1200 \mathrm{SiC}$ paper, polished up to $1 \mu \mathrm{m}$ and etched using Keller's reagent to reveal the resulting microstructure by optical microscopy.

Evaluation of the metal recovery yield and dross generation was performed assuming that the yield of the initial molten pool was $100 \%$ and that dross generation was only due to the aluminium briquettes.

\section{Experimental Results}

Results presented on this section are the average values of 3 experiments for each processing condition.

Influence of Briquetting Pressure on the Briquettes Moisture Content and Density. After machining the swarf average moisture content was $15 \%$ and decreased to about $7 \%$ after 12 hours decanting. After being centrifuged it decreased to an average value of $3.2 \%$, and to values below $3 \%$ after briquetting, as presented in Table 1.

Table 1 - Influence of briquetting pressure on the briquettes moisture content and density

\begin{tabular}{ccccc}
\hline Pressure (bar) & Initial weight $(\mathrm{kg})$ & Final weight $(\mathrm{kg})$ & Moisture content $(\%)$ & Density \\
\hline 300 & $4.84 \times 10^{-1}$ & $4.70 \times 10^{-1}$ & 2.89 & 2.01 \\
400 & $4.90 \times 10^{-1}$ & $4.78 \times 10^{-1}$ & 2.45 & 2.09 \\
500 & $5.08 \times 10-^{1}$ & $4.97 \times 10^{-1}$ & 2.17 & 2.14 \\
\hline
\end{tabular}

Influence of Briquetting Pressure on Al Recovery Rate / Dross Generation. The main problems when melting machining swarf is its high volume-to-weight ratio that will make it to float at the top of the liquid pool, increasing the probability of hydrogen pick-up from the atmosphere, as well as formation of oxide skins. Therefore, the best route is to compact the swarf prior to melting it, in order to melt the swarf blocks inside the molten pool. Experiments were carried out using briquettes compacted at different pressures, and melting at different temperatures. The best recovery yields were obtained for 400 bar briquetting pressure, and decreased both for higher and lower pressures, for both temperatures (Table 2). 
Table 2 - Influence of briquetting pressure in the aluminium recovery yield and dross formation, for different melting temperatures and $50 \%$ briquettes in the melting stock

\begin{tabular}{|c|c|c|c|c|c|c|c|c|c|}
\hline \multirow{2}{*}{$\begin{array}{c}\mathrm{P} \\
\text { (bar) }\end{array}$} & \multirow{2}{*}{$\begin{array}{c}\mathrm{T} \\
\left({ }^{\circ} \mathrm{C}\right)\end{array}$} & \multirow{2}{*}{$\begin{array}{l}\text { Melting } \\
\text { time } \\
\text { (min) }\end{array}$} & \multicolumn{3}{|c|}{ Melting charge $(\mathrm{kg})$} & \multicolumn{2}{|c|}{ Poured (kg) } & \multicolumn{2}{|l|}{$(\%)$} \\
\hline & & & $\begin{array}{l}\text { Ingot } \\
(1)\end{array}$ & $\begin{array}{l}\text { Swarf } \\
(2)\end{array}$ & $\begin{array}{l}\text { Total } \\
(2+1)\end{array}$ & $\begin{array}{c}\text { Metal } \\
(3)\end{array}$ & $\begin{array}{c}\text { Dross } \\
(4)\end{array}$ & $\begin{array}{c}\text { Recovery } \\
{[(3-1) /(2)]^{*} 100}\end{array}$ & $\begin{array}{c}\text { Dross } \\
(4 / 2)^{*} 100\end{array}$ \\
\hline 300 & 750 & 40 & 10.20 & 10.10 & 20.30 & 16.80 & 3.10 & 65.30 & 30.70 \\
\hline 400 & 750 & 45 & 9.90 & 10.60 & 20.50 & 18.30 & 1.90 & 79.20 & 17.90 \\
\hline 500 & 750 & 50 & 9.85 & 10.40 & 20.25 & 17.50 & 2.30 & 73.60 & 22.10 \\
\hline 300 & 800 & 42 & 9.95 & 10.10 & 20.05 & 16.70 & 3.00 & 66.80 & 29.70 \\
\hline 400 & 800 & 48 & 10.00 & 9.90 & 19.90 & 18.10 & 1.65 & 81.80 & 16.70 \\
\hline 500 & 800 & 53 & 9.85 & 10.10 & 19.95 & 17.40 & 2.20 & 74.80 & 21.80 \\
\hline 300 & 850 & 42 & 10.20 & 9.90 & 20.05 & 16.70 & 3.10 & 66.20 & 31.30 \\
\hline 400 & 850 & 50 & 9.90 & 10.05 & 19.95 & 18.10 & 1.70 & 81.60 & 16.90 \\
\hline 500 & 850 & 53 & 9.90 & 10.10 & 20.00 & 17.50 & 2.30 & 75.20 & 22.80 \\
\hline
\end{tabular}

This can be explained by different briquettes porosity levels associated to different compression values - higher briquetting pressures lead to lower porosity levels in the briquettes. In those briquettes compressed at 300 bar, the molten metal could easily penetrate the interstitials between the swarf fragments, making the swarf melting easier and faster, but at the same time it floated to the surface and a great amount of dross was formed. This was confirmed by the lower melting time of those briquettes. Metal penetration was more difficult in briquettes compacted at 500 bar and, as a consequence, the melting time was higher. In fact, the high volume of dross generated when those briquettes were used suggests that the melting time was probably not enough, and dross still contained a significant metal fraction. The recovery rate could probably be increased by increasing the total melting time. The melting temperature didn't affect the recovery yield significantly, for every briquetting pressure. Moreover, the melting time, which was controlled by the dissolution rate of the swarf briquettes, was almost the same for every temperature. This suggests that ultrasonic vibration of the melt may have played a crucial role in the dissolution kinetics of the swarf briquettes, promoting the oxide films destruction and consequent metal release since the early melting stages, thus not increasing significantly the melting time even for higher melting temperatures.

Influence of Atmosphere on Al Recovery Rate / Dross Generation. It is well known that the melting atmosphere can play an important role in the Al recovery yield, mainly if melting is carried out in induction furnaces, due to the intense stirring effect of the pool caused by the electromagnetic fields. Melt stirring and high processing temperatures increase the dissolution rate of hydrogen in aluminium melts and oxide formation, therefore the amount of dross that forms during melting. A protective atmosphere of inert gas will decrease that effect and improve the metal recovery yield. Table 3 presents the results of a set of experiments using a protective argon atmosphere, for $750^{\circ} \mathrm{C}$ melting temperature and using briquetting pressures of 300, 400 and 500 bar.

Table 3 - Influence of briquetting pressure in the aluminium recovery yield and dross formation, for $750^{\circ} \mathrm{C}$ melting temperatures and $50 \%$ briquettes in the melting stock, with the melting processed under argon atmosphere

\begin{tabular}{|c|c|c|c|c|c|c|c|c|c|}
\hline \multirow{2}{*}{$\begin{array}{c}\mathrm{P} \\
\text { (bar) }\end{array}$} & \multirow{2}{*}{$\begin{array}{c}\mathrm{T} \\
\left({ }^{\circ} \mathrm{C}\right)\end{array}$} & \multirow{2}{*}{$\begin{array}{l}\text { Melting } \\
\text { time } \\
(\min )\end{array}$} & \multicolumn{3}{|c|}{ Melting charge $(\mathrm{kg})$} & \multicolumn{2}{|c|}{ Poured (kg) } & \multicolumn{2}{|l|}{$(\%)$} \\
\hline & & & $\begin{array}{c}\text { Ingot } \\
(1)\end{array}$ & $\begin{array}{c}\text { Swarf } \\
\text { (2) }\end{array}$ & $\begin{array}{l}\text { Total } \\
(2+1) \\
\end{array}$ & $\begin{array}{c}\text { Metal } \\
\text { (3) }\end{array}$ & $\begin{array}{c}\text { Dross } \\
(4)\end{array}$ & $\begin{array}{c}\text { Recovery } \\
{[(3-1) /(2)]^{*} 100}\end{array}$ & $\begin{array}{c}\text { Dross } \\
(4 / 2)^{*} 100\end{array}$ \\
\hline 300 & 750 & 36 & 9.85 & 10.20 & 20.05 & 18.80 & 1.10 & 87.70 & 10.80 \\
\hline 400 & 750 & 40 & 9.95 & 10.10 & 20.05 & 19.50 & 0.50 & 94.60 & 5.00 \\
\hline 500 & 750 & 48 & 10.00 & 9.90 & 19.90 & 19.10 & 0.70 & 91.90 & 7.10 \\
\hline
\end{tabular}

It is clear the beneficial effect of the argon atmosphere in the aluminium recovery yield. The highest recovery yield was $94.6 \%$, obtained for 400 bar briquettes, which is the highest value referred so far 
in the bibliography. Nevertheless, yields obtained for 300 and, particularly, 500 bar, were also very high, revealing that melt protection and ultrasonic processing are perhaps the most crucial factors in the recovery process. When compared with non-protected melts (Table 2), metal recovery was 34, 19 and $25 \%$ higher for 300, 400 and 500 bar briquetting pressures, respectively. This proves that the low recovery yield detected when briquettes compressed at 300 bar were melted without protection was due to its oxidation when loosen particles reached the melt surface before being dissolved.

Influence of Melting Charge Composition on Al Recovery Rate / Dross Generation. The ideal size of the initial molten pool is not known, and it will depend on the briquettes shape and size, the furnace dimensions and the tools used to plunge the compacted swarf. On this work the effect on the metal recovery efficiency was evaluated for molten pools of Al returns corresponding to $25,30,35,40,45$ and $50 \%$ of the total melting charge. Melting charges were completed with briquettes of $\mathrm{Al}$ swarf compacted at 400 bar. The highest aluminium recovery rates (approximately $95 \%$ ) were obtained for initial molten pools of $50 \%$, slightly decreasing for initial molten pools below that value. However, melting time increased very much as the volume of the molten pool decreased. For small molten baths (around 25\%), the recovery yield decreased until values around $80 \%$ (see Fig.3). This effect was probably due to insufficient volume of the initial molten pool that could not avoid the contact between the briquettes and the atmosphere. Since perfect gaseous protection of the molten bath is never perfect, swarf oxidation may have occurred leading to higher dross generation and lower metal recovery.

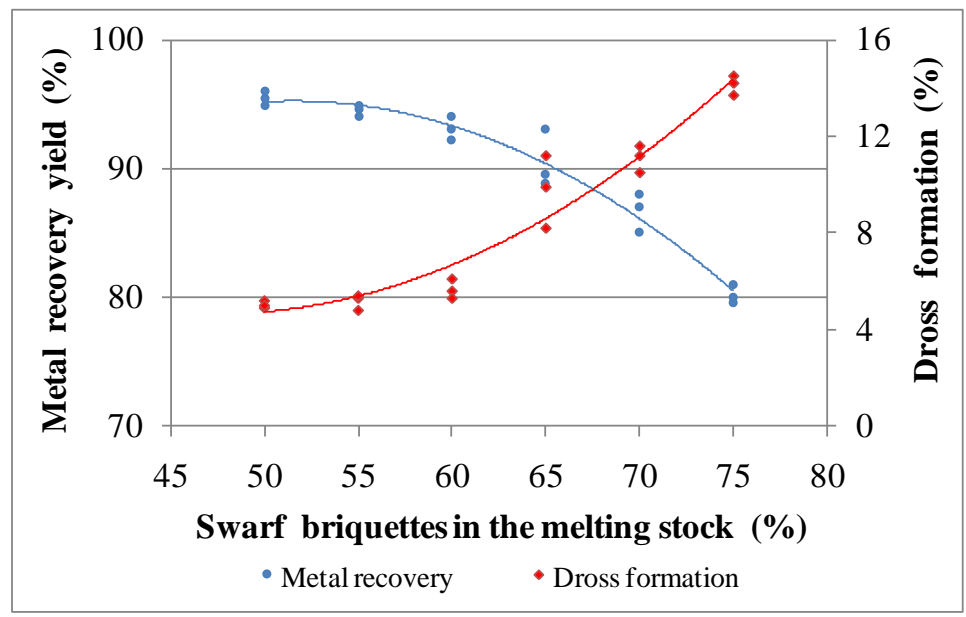

Figure 3 - Influence of the briquettes content in the melting stock on the metal recovery yield and dross formation

Influence of Processing Parameters in the Final Gas Content of the Melts. As referred in section "Melting Operation" samples were taken to evaluate the gas content of the melt. Due to the well known difficulties associated to hydrogen measurement in Al melts, the gas content was qualitatively evaluated using the RPT test and the apparent density measurement to quantify the samples density, based on its theoretical volume mass $\left(2.78 \mathrm{~kg} / \mathrm{dm}^{3}\right)$. In every experiment, the alloys density was evaluated twice: immediately after melting and after the homogenization period. In every experiment, no significant differences in density were detected between those two moments, revealing that the ultrasonic unit performed degassing during the entire processing and the molten pool was already fully degassed after melting. Density average values between 2.69 and 2.72 were found in every melt, corresponding to 98 to $99 \%$ of the theoretical alloy density.

Samples Microstructure. Figure 4 shows the microstructure of a cast sample corresponding to a melt processed under argon atmosphere, using $750^{\circ} \mathrm{C}$ melting temperature and $50 \%$ briquettes compacted at 400 bar in the melting stock. Refinement of the Al dendrites and fully silicon 
modification promoted by the Al-Ti-B and Al-Sr master alloy, respectively, is clearly seen. It is important to notice the absence of gas porosities, revealing the extremely high efficiency of ultrasonic degassing.
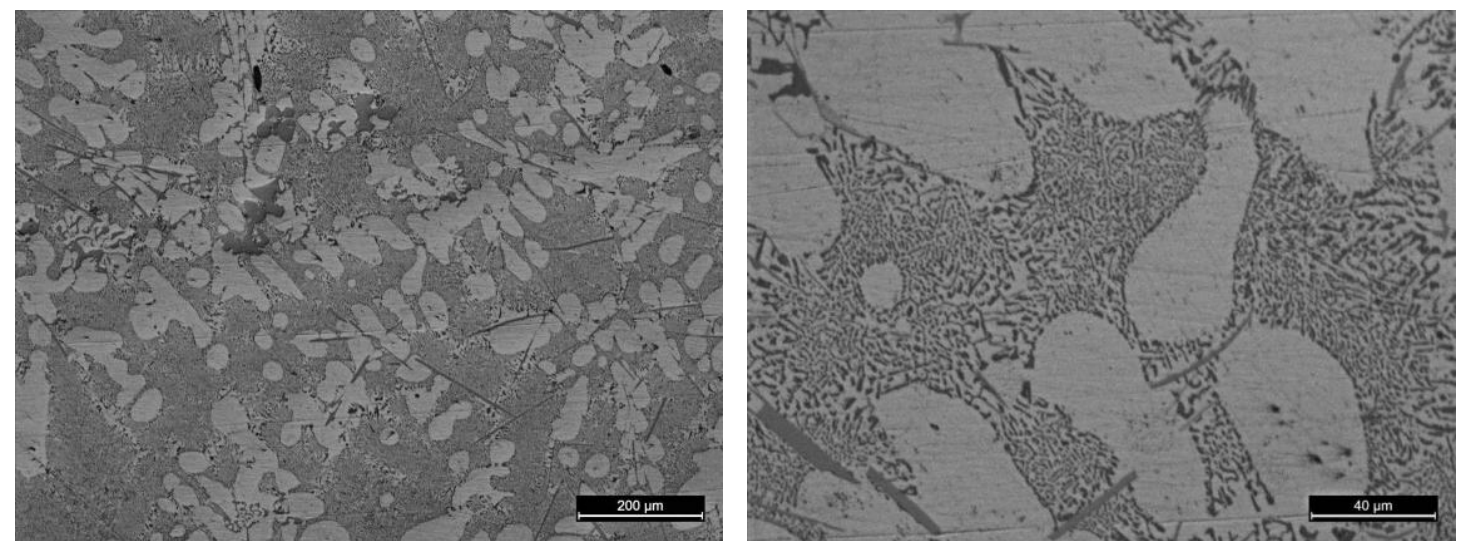

Figure 4 - Microstructure of a AlSi12Cu1 cast sample produced from foundry returns and swarf briquettes, refined and modified with Al-Ti-B and Al-Sr, respectively. No gas porosities are present.

\section{Conclusions}

- An efficient and environmentally friend swarf recycling technique was developed and its is ready for widespread dissemination;

- The combined effect of induction melting, argon protective atmosphere and ultrasonic vibration of the melt during the entire processing are the crucial factors of the process, and can lead to $95 \%$ Al recovery yield;

- Besides those factors, the briquetting pressure is also a major factor of the process. For the processing conditions used on this work, the most efficient briquetting pressure was 400 bar;

- The melting temperature has minimal influence in the recovery yield and dross formation;

- The Al recovery yield increases as the content of swarf briquettes in the melting charge decreases. This effect is stronger for briquette contents above $60 \%$

\section{References}

[1] Aluminium Association Reports. www.aluminium.org visited April 2, 2011.

[2] S. K. Das et al., The worldwide aluminium economy. JOM 59 (11) (2007) 57-63.

[3] G.O Verran and U. Kurzawa, An experimental study of aluminium can recycling using fusion in induction furnace". Res. Cons. and Rec. 52 (5) (2008) 731-736.

[4] J.B. Gatti et al., Recycling of aluminium can in terms of life cycle inventory (LCI). Int. J. Life Cycle Ass. 13 (3) (2008) 219-225.

[5] M. Samuel, Reinforcement of recycled aluminium-alloy scrap with Saffil ceramic fibres. J. Mat. Proc. Tech. 142 (2003) 295-306.

[6] J.B. Fogagnolo et al., Recycling of aluminium alloy and aluminium matrix composite chips by pressing and hot extrusion. J. Mat. Proc. Tech. 143-144 (2003) 792-795.

[7] Y. Chino et al., Mechanical properties of Mg-Al-Ca alloy recycled by solid-state recycling. Mat Trans. 46 (12) (2005) 2592-2595.

[8] L.B. Hussain and I.A.A. Hakim, Recycling and formulation of aluminium scrap via mass balance die casting and forming. Mat. Man. Proc. 22 (7-8) (2007) 916-921.

[9] R. Uscinowicz, Creep of a laminated aluminium-zinc composite. Mat Sci., 44(2)(2008) 283289

[10]H. Puga et al., The influence of processing parameters on the ultrasonic degassing of molten AlSi9Cu3 alloy. Mat. Let. 63 (2009) 806-808. 